\title{
INFLUENCE OF HIKING IN SPORTS CLASSES IN UNWE ON STUDENTS ATTITUDES TOWARDS THE NATURE
}

\author{
V. Jordanov ${ }^{1}$, Zh. Georgiev ${ }^{2}$, E. Jordanov ${ }^{3}$ \\ ${ }^{1}$ Department of Physical Education and Sport, University of National and World Economy, Sofia, \\ Bulgaria \\ ${ }^{2}$ Department of Physical Education and Sport, University of Forestry, Sofia, Bulgaria \\ ${ }^{3}$ Department of Foreign Languages and Sports, "Department of Physical Culture and Sports", \\ University of Mining and Geology "St. Ivan Rilski”, Sofia, Bulgaria
}

\begin{abstract}
The problems of pollution and the destruction of nature have been a part of us for a long time. No matter how much people are interested and trusted in all the threatening forecasts, no one can deny the tremendous changes that have taken place in our environment over the last century. Addressing these problems is one of the major tasks of future generations.

The study aims to track the impact of hiking as a possible sport at UNWE on students' attitudes toward nature protection. The study involved 229 students enrolled in various sports at the university, divided into two groups. The experimental group (161) - including students walking in the mountains and the control group (68) - including students attending other sports at UNWE. Both surveys were conducted at the beginning and end of the school year, using the "Questionnaire of the attitude towards the protection of nature".

The results show that the students who participated in the hiking activities in the mountains increase statistically significantly the actions they take to protect nature. No such changes are observed in students from other sports. In terms of knowledge, there are no significant changes in both groups.
\end{abstract}

Key words: knowledge, action, environmental problems, questionnaire, pollution, analysis, conclusion

\section{INTRODUCTION}

The problems associated with pollution and the destruction of nature have been around for a long time. For several generations now, news has emerged about the pernicious impact of various types of human activity on the face of the Earth. Regardless of whether people are interested in and trusting in all threatening forecasts, no one can deny the tremendous changes that have taken place in our environment over the last century.

Continuous awareness of natural problems has left a mark on people. Although to varying

\footnotetext{
*Correspondence to: V. Jordanov, Zh. Georgiev, E. Jordanov' Department of Physical Education and Sport, University of National and World Economy, Student Town, Sofia, Bulgaria, e-mail: venzislavjordanov@gmail.com,phone (+359) 879616236
}

degrees of awareness and action were taken, many of today's residents of developed countries are trying to comply with environmental standards (1).

On the one hand, the influence is on the individual. Habits such as separate garbage collection, participation in nature-cleaning campaigns, or even environmental pollution have become part of our normal lives. On the other hand, a person can influence knowledge and behavior on corporations and public policy. Emissions taxes, expansion of protected areas and the use of alternative sources of energy are a small part of the measures taken that only a few years ago few countries would have paid attention to (2).

Addressing these problems is one of the major tasks of future generations. This is especially 
true for students. It is the years of study that are the stage in which people build their future positions. So, to what extent they will understand the problems of Nature depend on what efforts they will make to preserve it because her knowledge is the greatest precondition for this $(3,4)$.

Perhaps the most enjoyable and accessible way to meet nature is mountain tourism. Usually, just as a student, people are passionate about hiking. One of the main opportunities to take this route is to join hiking groups in choosing a sport at UNWE. In addition to its influence as an excellent tool for physical activity and active rest, it also aims to teach people to love the mountain and to be in harmony with it (5, 6). This is of great importance for economics students, both because of their personal responsibilities in nature conservation and because of future decisions that they would face in holding positions of responsibility in the state apparatus. Such a quality would be extremely valuable to the profession of future economists (7).

To what extent, however, does hiking in the UNWE classes have a positive impact on students' attitudes toward nature protection? Addressing this question is at the heart of our choice of topic for this study.

\section{PURPOSE}

The purpose of the study is to investigate the impact of hiking activities as a sport at UNWE on students' attitudes toward nature protection.

To achieve our goal, we have set the following tasks:

1. To investigate at the beginning of the school year the attitude towards nature protection in students from hiking groups and in students attending other sports.

2. Compare the outputs of students from the two groups and see if there are any differences related to the choice of sport.

3. Repeat the study at the end of the school year.

4. To compare the results in the two semesters of the two groups and to determine the possible differences.

\section{METHODS}

To achieve this, we used "Questionnaire for studying the attitude towards nature" (1). The questionnaire was developed specifically for the purposes of this study. It contains two scales related to nature conservation:
"The Knowledge "scale is related to the general awareness of the researcher on environmental issues. Questions such as: "Human activity negatively affects ecosystems" and "Alternative energy sources would significantly reduce pollution".

The second scale, "Actions", refers to the specific actions of a person to limit the harmful effects on nature. Includes issues such as: "I collect my garbage separately" and "I regularly participate in environmental campaigns cleanings, tree planting, etc."

A 5-point Likert-type scale is used. The results obtained were processed using the specialized program IBM "SPSS" 19.0 and "Excel". Statistical methods included:

- Variational analysis;

- Comparative analysis - Student's T-test for independent samples.

The distribution of values was determined by the Kolmogorov - Smirnov test. Normal or close to normal distribution is judged by limits of significance above $0.05(\mathrm{p}(\mathrm{Z})>0.05)$.

\section{ORGANIZATION OF THE STUDY}

The first study took place in October 2018 at the beginning of the winter semester. It was attended by 229 students, divided into two groups. Experimental Group (161) - Including Students Attending Hiking Classes and Control Group (68) - Including Students from Basketball, Table Tennis, Tennis, Climbing, Fitness, Callanetics and Aerobics. At the end of the summer semester, we repeated the study with 129 subjects - 89 from the experimental group and 40 from the control group.

\section{RESULTS}

The results of the data analysis between the two groups at the beginning of the year are presented in Table 1 and Figure 1. We make this comparison to determine whether students who choose hiking as a sport differ in a more developed attitude toward nature protection

The first thing that impresses is the presence of higher values of the "Knowledge" scale when developing the questionnaire than the "Actions" scale. Differences of about one unit indicate that students have more information about Earth protection issues than the actual steps they take to implement them.

Returning to the comparison between the two groups at the beginning of the year, we can point out that the choice of hiking is not 
influenced by the different attitude of the students towards nature conservation. Our results show just that. In terms of knowledge, the experimental group scores were 4.10 versus 4.03 in the control group. This difference is not statistically significant. There is a greater difference in values on the "Actions"scale. The result of the students chose hiking as a sport is 3.00 , while that of the sportsmen in the hall is 2.79 . However, the difference is not statistically significant, which does not allow us to take it into account.

Table 1. Comparative analysis of the attitude to nature protection between the two groups at the beginning of the year

\begin{tabular}{|l|l|l|l|l|l|l|l|}
\hline \multirow{2}{*}{ Kroup } & Sport & $\mathbf{N}$ & $\mathbf{M}$ & SD & $\mathbf{p}(\mathbf{Z})$ & t & Sig. \\
\hline \multirow{2}{*}{ Actions } & Hiking & 161 & 4,108 & 0,537 & 0,123 & \multirow{2}{*}{0,623} & \multirow{2}{*}{0,531} \\
\cline { 2 - 9 } & Other sports & 68 & 4,027 & 0,659 & 0,087 & & \\
\cline { 2 - 8 } & Hiking & 161 & 2,997 & 0,717 & 0,111 & \multirow{2}{*}{$-1,412$} & 0,097 \\
\hline
\end{tabular}

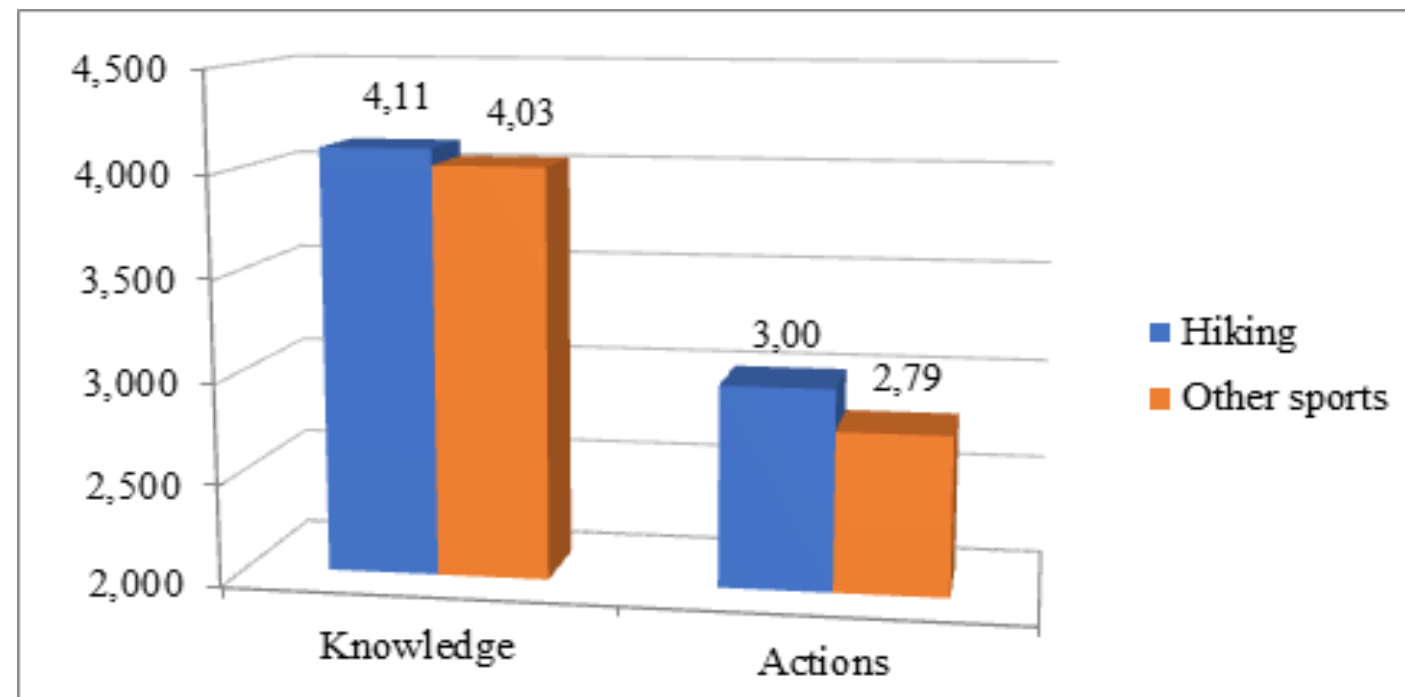

Figure 1. Comparative analysis of the attitude towards nature protection between the two groups at the beginning of the year

Table 2 and Figure 2 present a comparative analysis of the results obtained at the beginning and end of the year for the two groups on the "Knowledge" scale. The data show that there are no significant differences between students at the beginning and end of the semester $(\mathrm{t}=-0.553$; $\mathrm{sig}=0.581)$. The situation in the control group is similar.
The results obtained at the beginning of the school year do not differ significantly from those at the end of the second semester $(\mathrm{t}=$ 0.404 ; $\operatorname{sig}=0.687)$. These data show that walking in the mountains during UNWE sports hours does not significantly develop knowledge about nature conservation.

Table 2. Comparative analysis of the "knowledge" scale in the two groups at the beginning and end of the semester

\begin{tabular}{|l|l|l|l|l|l|l|l|}
\hline \multirow{2}{*}{ Group } & Research & $\mathbf{N}$ & $\mathbf{M}$ & $\mathbf{S D}$ & $\mathbf{p}(\mathbf{Z})$ & $\mathbf{t}$ & Sig. \\
\hline \multirow{2}{*}{ Hiking } & Beginning & 161 & 4,108 & 0,537 & 0,123 & $-0,553$ & 0,581 \\
\cline { 2 - 8 } & End & 89 & 4,155 & 0,593 & 0,179 & & \\
\hline \multirow{2}{*}{ Other sports } & Beginning & 68 & 4,027 & 0,659 & 0,087 & $-0,404$ & 0,687 \\
\cline { 2 - 8 } & End & 40 & 4,077 & 0,500 & 0,079 & & \\
\hline
\end{tabular}




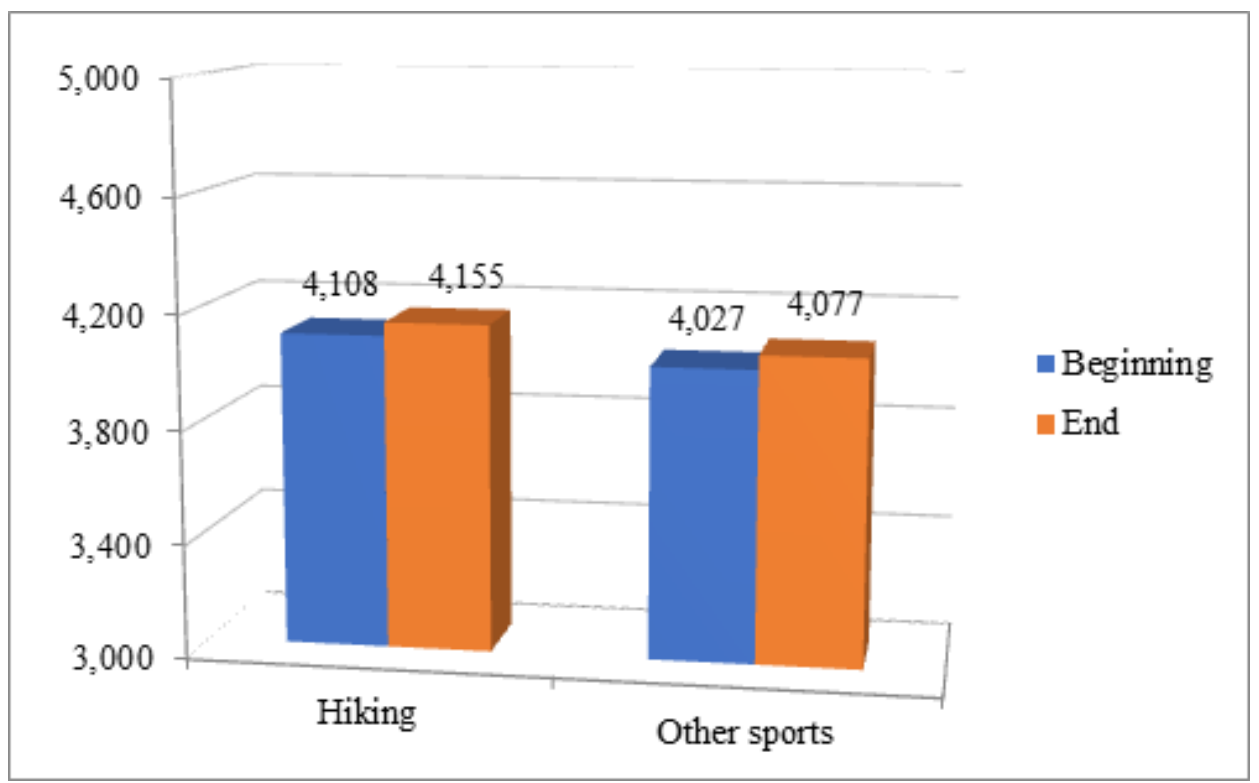

Figure 2. Comparative analysis of the "knowledge" scale in the two groups at the beginning and end of the semester

The results of the comparative analysis of the data from the "Actions" scale between the beginning and the end of the study are presented in Table 3 and Figure 3. From the values obtained, we can see that hiking has a statistically significant increase in the results at the end of the school year $(\mathrm{t}=-3.681$; sig $=$ $0.00)$. On the other hand, the difference in the result of the students who practiced other sports at UNWE has no statistical significance $(\mathrm{t}=-1.451 ; \mathrm{sig}=0.126)$. This comparison may suggest that walking the mountain during the physical education classes has a significant impact on the student's actions toward nature conservation.

Table 3. Comparative analysis of the "actions" scale for the two groups at the beginning and end of the semester

\begin{tabular}{|l|l|l|l|l|l|l|l|}
\hline \multirow{2}{*}{ Group } & Research & $\mathbf{N}$ & $\mathbf{M}$ & $\mathbf{S D}$ & $\mathbf{p}(\mathbf{Z})$ & $\mathbf{t}$ & Sig. \\
\hline \multirow{2}{*}{ Hiking } & Beginning & 161 & 2,997 & 0,617 & 0,111 & \multirow{2}{*}{$-3,681$} & \multirow{2}{*}{0} \\
\cline { 2 - 8 } & End & 89 & 3,338 & 0,554 & 0,224 & & \multirow{2}{*}{0,126} \\
\hline \multirow{2}{*}{ Other sports } & Beginning & 68 & 2,791 & 0,732 & 0,998 & \multirow{2}{*}{0,126} \\
\cline { 2 - 8 } & End & 40 & 2,957 & 0,645 & 0,326 & & \\
\hline
\end{tabular}

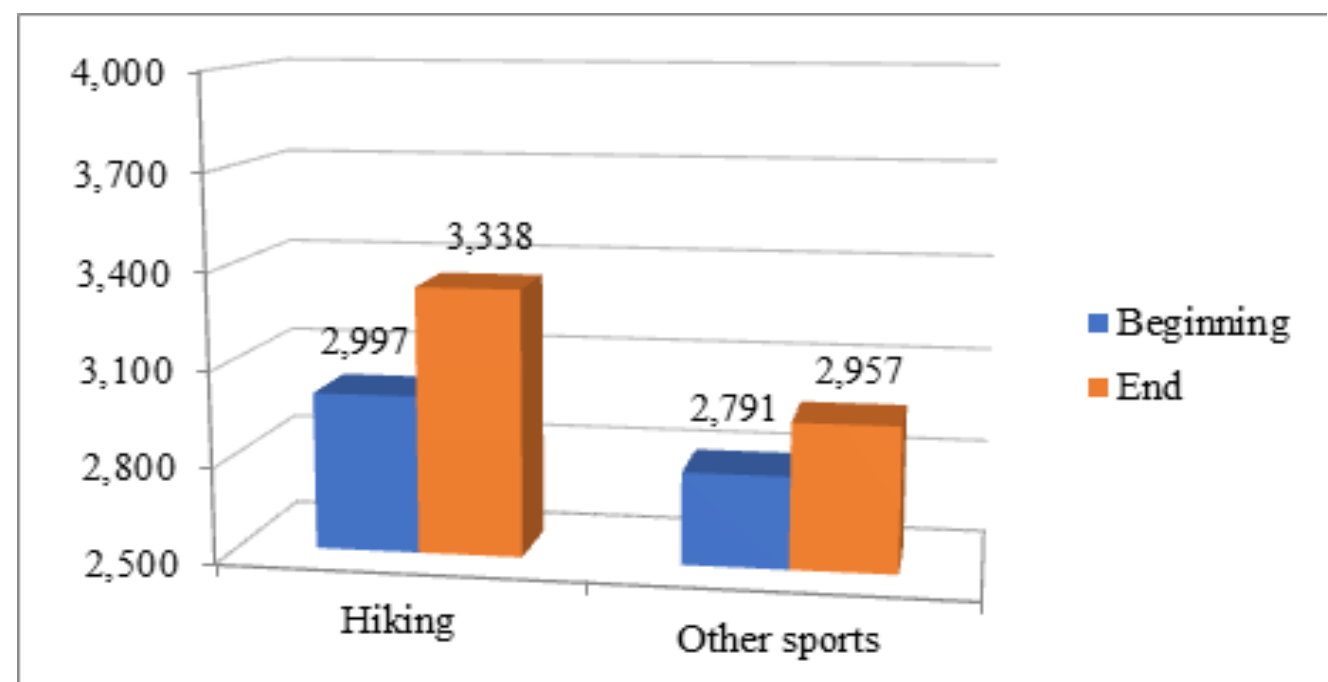

Figure 3. Comparative analysis of the "actions" scale for the two groups at the beginning and end of the semester 
Analyzing the data obtained, we can see another interesting trend. Awareness of students' environmental problems is relatively high and is unaffected by outcrops. On the other hand, it is the connection with the mountain, its beauty, contact with colleagues, teachers and even meeting with other tourists that made students change some of their habits and take more action in order to limit their harmful influence. This may suggest that regular visits to nature give rise to responsibility for its conservation, and understanding through experience is one of the best means of education.

\section{CONCLUSIONS}

1. Students who choose hiking at the beginning of the year do not have a stronger attitude towards nature conservation than their counterparts from other sports.

2. Mountain transitions, within the framework of UNWE sports, do not significantly increase students' knowledge of environmental problems.

3. Hiking lessons at UNWE have had a significant impact on the actions young people take to conserve nature.

\section{REFERENCES}

1. De Groot, J. I. M., Steg, L. Value orientations to explain beliefs related to environmental significant behavior. Environ, Behav, pp. 330-354, 2008.
JORDANOV V., et al.

2. Hansla, A., Gamble, A., Juliusson, A., Gärling, T. The relationships between awareness of consequences, environmental concern, and value orientations. J. Environ. Psychol. 28, pp. 1-9, 2008.

3. Bouman, T., Steg., L., Kiers, H. Measuring Values in Environmental Research: A Test of an Environmental Portrait Value Questionnaire. Frontiers in Psychology 9: pp. 1-15, 2018.

4. Nilsson, A., Hansla, A., Heiling, J. M., Bergstad, C. J., Martinsson, J. Public acceptability towards environmental policy measures: value-matching appeals. Environ. Sci. Policy 61, pp. 176-184, 2016.

5. Burdarev, D., Garkov, V. et al., Hiking, Mountaineering, Orientation. Textbook (II revised edition). NSA PRES, Sofia, 2007.

6. Popyordanov, L., Damyanov, M. et al., Mountains nearby: Handbook of the mountain guide and the good mountaineer. Odisea-IN, Sofia, 2012.

7. Stavreva, I., Stavrev, S. Requirements for motor and intellectual qualities for specialists in the mining industry and the economic profession and their comparison. International Scientific Conference "Teacher Education - Traditions and Modernity", "St. Cyril and St. Methodius" University of Veliko Tarnovo. Collection of reports, A \& B, 2015. 